\title{
A mulher negra in(visível) entre o açúcar e o tabaco, do cubano Fernando Ortiz
}

\author{
La mujer negra en (visible) entre azúcar y tabaco, por el cubano Fernando \\ Ortiz
}
The black woman in(visible) between sugar and tobacco, by Cuban Fernando Ortiz

\section{Sandra Regina Marcelino Pinto ${ }^{1}$ Eliane da Silva ${ }^{2}$}

\begin{abstract}
Resumo
A história e conhecimentos sobre o açúcar e o tabaco foram magistramente descritos pelo escritor Fernando Ortiz no Ensaio Contrapunteo Cubano del Azucar y del tabaco, de 1940. Diante das informações presentes na reunião dos textos deste eminente escritor, busco desenvolver neste artigo um contraponto que possa conectar mais de perto os dois produtos citados e a mulher negra, que outrora havia sido sequestrada de África para recomeçar, forçadamente, sua vida na América Latina. A indagação se dá pela não presença dessas mulheres, nominalmente, num enredo que se desenrola em Cuba, país tão repleto de africanos e seus descendentes.
\end{abstract}

Palavras-chave:Mulher; Tabaco e açúcar; Cuba; Ortiz.

\section{Resumen}

La historia y el conocimiento del azúcar y el tabaco fueron magistralmente descritos por el escritor Fernando Ortiz en el Ensayo Contrapunteo Cubano del Azúcar y del tabaco, 1940. En vista de la información presente en la reunión de los textos de este eminente escritor, trato de desarrollar en este artículo un contrapunto que pueda conectar más estrechamente los dos productos mencionados y la mujer negra, que una vez fue secuestrada de África para comenzar a fuerza su vida en América Latina. El tema la ausencia de estas mujeres, nominalmente, en un complot que tiene lugar en Cuba, un país lleno de africanos y sus descendientes.

Palabras clave: Mujer; Tabaco y azúcar; Cuba; Ortiz.

\section{Summary}

The history and knowledge of sugar and tobacco were masterfully described by the writer Fernando Ortiz in the Ensaio Contrapunteo Cubano del Azucar y del tabaco, 1940. In view of the information present in the meeting of

\footnotetext{
${ }^{1}$ Mestra em Filologia e Língua Portuguesa pela USP/SP. Doutora em Língua Portuguesa pela PUC/SP. Professora de espanhol no Colégio São José dos Campos; São Paulo/SP, Brasil; eliane1silva@gmail.com.

${ }^{2}$ Mestra em Filologia e Língua Portuguesa pela USP/SP. Doutoranda em Literatura Comparada - UFF/RJ. Membra do Centro de Estudo, Pesquisa e Extensão em Educação, Gênero, Raça e Etnia- CEPEGRE/UEMS; Rio de Janeiro/RS, Brasil; eliane1silva@gmail.com.
} 
the texts of this eminent writer, I try to develop in this article a counterpoint that can connect more closely the two products mentioned and the black woman, who had once been kidnapped from Africa in order to forcefully begin her life anew in Latin America. The question is about the non presence of these women, nominally, in a plot taking place in Cuba, a country so full of Africans and their descendants.

Keywords: Woman; Tobacco and sugar; Cuba; Ortiz.

\section{Introdução}

O tema foi pensando no momento de uma indagação pessoal para buscar entender o motivo pelo qual as mulheres negras são pouco mencionadas nas obras de escritores latino-americanos, mais precisamente tratando-se de autores Cubanos, visto que, no Brasil, no início do século $\mathrm{XX}$, recorte temporal desta pesquisa, alguns literatos ao menos inseriam as mulheres negras em suas obras, como se, sem elas, não fosse possível obter histórias interessantes e satíricas, pensando mais a fundo, tristes, pois estas, ao serem retratadas, era num sentido jocoso, sexual, libidinoso, in(visíveis). As literaturas do início do século XX, a saber, escrita basicamente pelos homens, insistiu em não apresentar a mulher negra que foi base para a construção social de muitos povos nos diversos países latino-americanos.

Quando se lê Fernando Ortiz, Jorge Luiz Borges, Gilberto Freyre, observa-se a voz masculina que se nucleia nos textos desses, apresentando uma visão de mundo enquanto cidadãos intelectuais que bebiam da literatura anglo-saxônica, que observavam as ocorrências em seus países de origem de forma muitas vezes românticas, prendendo o olhar atento dos leitores da época para as principais ocorrências de seus meios culturais. Nestes autores, observa-se, quase não há menções da existência de uma família afrocubana, aparece ora o homem e, minimamente, a mulher negra.

No Brasil, Cuba e Argentina, os processos de revoluções e independências, que envolveram a formação de seu povo, foi muito longo e duro, sem contar as ocorrências, como a eugenia e a miscigenação, transculturação, este, cunhado por Ortiz na década de 40. Já Simon Bolívar, em 1819, iniciou os primeiros rascunhos sobre a miscigenação:

\footnotetext{
“Tenhamos presente que nosso povo não é o europeu, nem o americano do norte, é antes um composto de África e América do que uma emanação da Europa, pois que a Espanha mesma deixa de ser Europa pelo seu sangue africano, pelas suas instituições e por seu caráter. É impossível caracterizar com propriedade a que família humana pertencemos. A maior parte do indígena se aniquilou, o europeu mesclou-se com o americano e com o africano e este mesclou-se com o índio e com o europeu. Nascidos todos do seio de uma mesma mãe, nossos pais, diferentes em origem e em sangue, são estrangeiros, e todos diferem visivelmente na epiderme; esta dessemelhança traz uma ligação da maior importância" (BOLIVAR, 1819).
} 
Tais informações sobre uma nação que poderia ser irmã, com seus povos misturados essas centrais em muitos dos textos de escritores latino-americanos com tendência a um nacionalismo mais positivo, mesmo diante das atrocidades da escravidão do negro e do índio, mesmo diante do assassinato de muitos desses povos.

Ainda, os países latinos em questão passaram pelo regime de colonização e escravização em massa, sendo colonizados por países que se autodenominavam soberanos, como Portugal, Estados Unidos, Espanha e França -, pensando nos países "hermanos", que falam inglês, francês, português de Portugal e espanhol.

Diante de tantos eventos históricos, onde estavam as mulheres negras? Como eram retratadas? Porque eram muito mais invisíveis que as mulheres brancas e, de certa forma, continuam assim atualmente mesmo que "fora do regime de escravidão"? Ser vista não significa que a mulher negra é visível, respeitada e ovacionada por seus talentos, seja na área de pesquisa, televisa, administrativa ou outros espaços de poder econômico.

\section{O açúcar e o tabaco - Ortiz}

O escritor cubano Fernando Ortiz iniciou os estudos focados em Cuba por meio de uma revista dirigida por ele, a Revista Bimestre Cubana e outros espaços de divulgação da cultura semelhantes -, conhecedor ferrenho da história, cultura, musicalidade e culinária do povo negro, ou seja, pesquisador da cultura afrocubana na área sociológica, folclórica, história, musicalidade e linguística, tratando-se de, categoricamente, elencar em seu ensaio “Contrapunteo Cubano del Azucar y del tabaco”as características variadas do açúcar e do tabaco, que, num primeiro momento parece dar vida aos adjetivos, transferindo-os para povos brancos e negros.

Observa-se neste texto de Ortiz, as artimanhas sobre o ensaio descritas por Adorno na década de 50, quando este ressalta que "o ensaio reflete o amado e o odiado em vez de apresentar o espiritual, segundo o modelo de uma ilimitada moral do trabalho, como criação a partir do nada (ADORNO, 1954).

Ortiz trata de conhecer o povo afrocubano em toda a sua diversidade, tentando entender por completo a "alma negra", sendo o ensaísta um dos primeiros a se interessar pelo assunto, o 
mesmo investiga profundamente as questões que envolvem os negros e usa ferozmente o material coletado em seus textos, no caso, no ensaio referente ao açúcar e o tabaco, mostrando as vicissitudes que atraem e repelem este dois produtos da natureza. E é nesta perspectiva que D. Fernando cria o termo transculturação.

Um pouco controverso e passível de mudanças de visão etnológica, Ortiz, até nos anos 20, acreditava que a unidade entre os povos que compunham Cuba só seria alcançada pela exclusão, pois os africanos e seus descendentes eram vistos como aqueles que não se integravam à nacionalidade vigente.

E esta não integralidade muitas vezes pode ser vista na obra de Ortiz, por exemplo, quando ele descreve que "Tanto o açúcar, branco, como o tabaco, marrom, são as personagens mais importantes da história de Cuba. Produtos vegetais do mesmo país e do mesmo clima, mas com uma distinção biológica que provoca radicais diferenças comerciais” (SKIRIUS, 1994, p. 71, grifo nosso).

Observa-se neste são diferenças que, segundo o autor, se refletem na história do povo cubano desde sua formação étnica até sua construção social, suas peripécias políticas e suas relações internacionais. Esses dois produtos são considerados os ícones da economia, essenciais para se conhecer a história cubana.

Assim, o autor a todo o momento faz dicotomias para descrever os dois produtos, levando o leitor a se infiltrar completamente no enredo em busca de informações novas sobre o açúcar e o tabaco. Os adjetivos presentes no ensaio, num dado momento, levam a leitura para uma indagação sobre se o que é descrito se refere à humanos, negros e brancos, ou aos vegetais, títulos do ensaio.

Questões que, levando em consideração a época da escrita, abre margem para expressões que possam depreciar um dado povo, oprimido, e alavancar um outro, dominante e os principais leitores dos livros e folhetins da época. Processo não diferente do Brasil, com as obras de Machado de Assis que, à sua época, buscava "esconder" um pouco da roupagem negra nas obras, mesmo tratando da temática da escravidão, não se via, por exemplo, algum tipo de falas contra os maus-tratos ou aproximação com as discussões abolicionistas da época. 
Escrevendo, em muitas situações, sobre temáticas que fossem agradáveis ao paladar literário dos europeus e seus descendentes. De toda maneira, o referido escritor, à sua maneira, sempre inseria personagens negras em suas obras, homens e mulheres, usando da ironia para expor as atrocidades sofridas pelos escravizados.

Vê-se, no entanto, Em Pai contra mãe, que não faltam colocações irônicas de Machado que denunciam o horror da escravidão, colocadas na voz do narrador, por exemplo, quando descreve a máscara de folha-de-flandres, que usavam para torturar os escravizados: "Era grotesca tal máscara, mas a ordem social e humana nem sempre se alcança sem o grotesco, e alguma vez o cruel." Ou também, quando descrevia os castigos aplicados pelos senhores, afirma que "o sentimento da propriedade moderava a ação, pois dinheiro também dói.”

Machado, assim como Ortiz, usava muitas comparações em seus textos, deixando o leitor esperançoso para transitar nos textos a fim de entender a história por completo, aumentando o leque de conhecimentos sobre enumeráveis assuntos, no caso de Ortiz, em torno dos dois sujeitos chaves da cultura e economia cubana, o açúcar e o tabaco.

Vê-se no ensaio de Fernando Ortiz informações sobre as condições climáticas favoráveis à cana de açúcar, indicando que a estação úmida e chuvosa é muito favorável ao rápido crescimento da cana em Cuba.

Observa-se ainda, conforme menciona Skirius (1994, p.74-79) que:

- O tabaco nasce, o açúcar se faz - fala do quão ricos são estes produtos da natureza, diferente de outras plantas, exaltando que se fuma o tabaco puro, sendo o açúcar, para se tornar puro tem que se recorrer a uma série de operações fisioquímicas, só par eliminar impurezas dos sucos, bagaços, cachaças.

- Tabaco é escuro, de negro e mulato, o açúcar é claro, de mulata a branca. O tabaco não muda de cor, nasce moreno e morre com a cor de sua raça. O açúcar muda de coloração, nasce pardo e se branqueia.

- Tabaco é perigoso e pecador, o açúcar é indispensável para o organismo, o tabaco necessário para o ser humano.

- Tabaco contém um tóxico, a nicotina, o açúcar, nutrientes, carboidratos. O Tabaco envenena, o açúcar sustenta. 
- Tabaco é uma planta medicinal, foi considerada assim pelos índios e europeus, é antiparasitário e emético (não encontrei uma tradução) - se usa a nicotina como antitetânico, contra a paralisia, como inseticida.

- O açúcar também é medicinal, e tem elementos constitutivos em nosso organismo fisiológico, podendo causar morte tanto pela carência do uso como pelo uso em excesso. Produtor de câncer, segundo pesquisa feita por um médico argentino, o Dr. Angel.

- Por isso, tanto o açúcar como o tabaco foram vendidos há séculos em farmácias.

- O tabaco visto como tentador para os espíritos - Quevedo dizia na Espanha que o tabaco havia feito mais mal que bem para os povos, é a fumaça que o rei católico usa.

Ainda, o mesmo produto cubano, o tabaco era visto como cúmplice de delinquência, criminal, usado pra envenenar, assassino, no século XVIII. Conta-se a lenda que um conde, o conde de Bocarme foi executado em Mons (Bélgica) por envenenar um cunhado valendo-se da nicotina, que do tabaco foi extraída.

Visto também como um vírus ou ultravírus filtrável e resiste como um demônio ao éter, ao cloro e à acetona, e a outros inimigos semelhantes sem perder sua efetividade. Lembrando que cada um dessas químicas são altamente concentradas, repelindo, comumente, qualquer outro resíduo.

É colocado ainda, na referida obra, como aquele produto que tem algo de mistério e sacralidade, visto que o consumo deixava as pessoas numa esfera inexplicável, isso quando o tabaco era usado puro.

Já o açúcar, visto como algo límpido, símbolo da paz e harmonia, concentrava uma quantidade de qualificativos que o exaltava diante do tabaco. Um era símbolo do pecado, o outro, da divindade, pois o todo o processo para se fazer o açúcar concentrava uma docilidade sem igual no viés de Ortiz, o qual salientou que "Se a vida é um eclipse com os seus dois focos no ventre e no sexo, o açúcar é a comida e a subsistência, o tabaco é o amor e a reprodução". Frase que resume bem esses dois produtos da natureza e trabalhado na terra pelos novos cubanos, vindos de África com sua sabedoria ancestral sobre cada um desses dois itens.

Ainda, observa-se em Skirius (1994, p. 80) que:

- fumar o primeiro tabaco é como um rito de passagem, quando se trata do sacro prova viril de fortaleza e domínio diante das amarguras

- $\quad$ símbolo de masculinidade 
- alguns povos indígenas (kusupaní) e negros da África (bantus), usam o tabaco como a iniciação de jovens na idade viril

- o açúcar é visto como um produto para crianças.

Contudo, as dicotomias existentes no ensaio de D. Fernando Ortiz traz uma gama de informações sobre o tabaco que, diga-se de passagem, teve um debruçar altamente qualificado no trato do conhecimento sobre estes produtos. De toda maneira, houve pouca menção às mulheres da época, no caso, as poucas referências à elas, não distinguia negras e indígenas das mulheres brancas. Sendo aquelas, claramente invisibilizadas, já que não eram, segundo mencionam alguns pesquisadores, consideradas parte da sociedade.

\section{Açúcar pra elas, tabaco pra eles. Mas quem são "elas"?}

No ensaio desenvolvido por Ortiz (1963), nota-se escritas dedicadas à transformação do charuto para o cigarro industrial, de papéis finos, usados por homens e mulheres, no caso destas, o autor menciona que o uso era apenas como ato político, para demonstrar que os tempos estavam mudando e as mulheres precisavam ocupar os espaços que outrora não tinham como direito.

O cigarro mudou de forma, e os tempos também, o tabaco não deixou de ser completamente um símbolo masculino, mas anarquista. De toda maneira, o autor suaviza as novas mudanças no gosto e na forma do cigarro como sendo mais receptivo às mulheres.

Ao analisar o ensaio, observa-se que a mulher ali indicada era somente aquela de padrões europeus, como se somente elas existissem naquele meio social, urbano ou rural, que tinha, como hoje, um pouco mais de vez e voz, uma família consistente e "perfeita", mesmo sendo estas completamente submissas aos seus maridos. E que se distanciava de outros grupos femininos, como as indígenas, negras e campesinas.

O autor, aparentemente, deixou de deixar transparecer no texto a efervescência de povos africanos que viviam no país e trabalhavam arduamente nos processos de transformação da cana em açúcar, e do tabaco em cigarro.

Tem-se a impressão de que a vida no negro, pela ótica do autor em estudo, era bastante rica de sentidos para se pesquisar, conhecê-los em sua integralidade, mas não o suficiente para que pudessem fazer parte dos enredos como pessoas honradas, que foram retiradas de seu habitat natural e colocadas numa região que estava em completa ebulição econômica, disputada por 
países que queriam aquela ilha tão tropical.Não à toda, os Estados tentaram colonizar a Ilha por duas vezes seguidas.

É importante levar em consideração também o fato de que até a primeira metade do século XVIII, quando se trata do comércio de escravos destinado a Cuba, houve um semi-equilibrio equilíbrio entre mulheres e homens. Já a partir da segunda metade, a maioria era homens, o que impossibilitou, em partes, a formação de casais negros, conforme salienta Fraginals Moreno (MORENO, 1980, p. 39).

Por hodierno, Cuba e as cubanas resistiram, mas ainda se busca pelas histórias mais completas do povo que ali viveu e vive atualmente. As mulheres negras, chefes de família, abusadas e forçadas pela sociedade eurocentrada a terem filhos mestiços a fim de "melhoria do país" existiram e também resistiram.

\section{Conclusão}

O processo vivenciado por Cuba e a formação de seu povo tem grande relevância no que os escritores daquela região desenvolviam no início do século XX. O presente artigo buscou trazer a possibilidade de busca de mulheres negras como personagens de referência nas obras desses intelectuais latino-americanos, no caso, Ortiz.

Neste sentido, este artigo abre uma margem para que estudos sejam feitos para que possamos conhecer na íntegra a história de mães, esposas, trabalhadoras negras que fizeram parte de Cuba no referido recorte temporal, que trabalharam nas lavouras de açúcar e tabaco, e consumiam os produtos. Bem como, possam surgir as mulheres escritoras que dedilham suas próprias histórias, sejam elas doces como o açúcar, ou venenosas como o tabaco, mas histórias reais que não invisibilizem as mulheres que descendem do povo africano.

\section{Referências}

ADORNO, Theodore. O ensaio como forma. In Notas de Literatura I. São Paulo: Duas cidades. Ed. 34, 2003.

MORENO FRAGINALS, Manuel. El Ingenio. La Habana: Editorial Ciencias Sociales, 1980.

ORTIZ, Fernando. Contrapunteo Cubano del Tabaco y del Azucar. Habana: Universidad Central de Las Villas, 1963. 
RELACult - Revista Latino-Americana de Estudos em Cultura e Sociedade

Revista Latinoamericana de Estudios en Cultura y Sociedad | Latin American Journal of Studies in Culture and Society V. 06, n 01, jan-abr., 2020, artigo $n^{\circ} 1851$ | claec.org/relacult | e-ISSN: 2525-7870

SKIRIUS, John. El ensayo hispanoamericano del siglo XX (Spanish Edition) (fourth). Tierra Firme, 1994. 